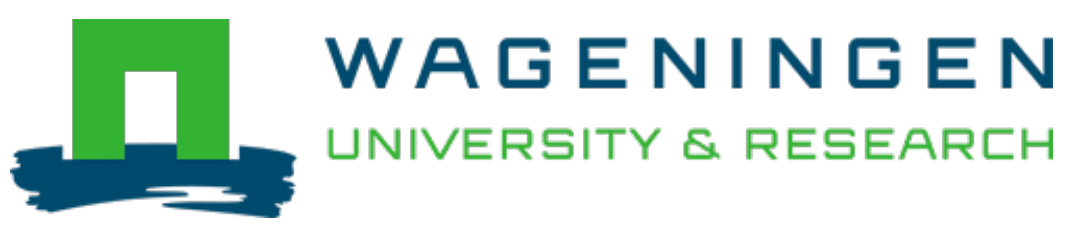

\title{
Field performance of different maize varieties in growth cores at natural and reduced mycorrhizal colonization : yield gains and possible fertilizer savings in relation to phosphorus application
}

Plant and Soil

Wang, Xin Xin; Werf, Wopke; Yu, Yang; Hoffland, Ellis; Feng, Gu et al https://doi.org/10.1007/s11104-020-04524-1

This publication is made publicly available in the institutional repository of Wageningen University and Research, under the terms of article $25 \mathrm{fa}$ of the Dutch Copyright Act, also known as the Amendment Taverne. This has been done with explicit consent by the author.

Article $25 \mathrm{fa}$ states that the author of a short scientific work funded either wholly or partially by Dutch public funds is entitled to make that work publicly available for no consideration following a reasonable period of time after the work was first published, provided that clear reference is made to the source of the first publication of the work.

This publication is distributed under The Association of Universities in the Netherlands (VSNU) 'Article $25 \mathrm{fa}$ implementation' project. In this project research outputs of researchers employed by Dutch Universities that comply with the legal requirements of Article $25 \mathrm{fa}$ of the Dutch Copyright Act are distributed online and free of cost or other barriers in institutional repositories. Research outputs are distributed six months after their first online publication in the original published version and with proper attribution to the source of the original publication.

You are permitted to download and use the publication for personal purposes. All rights remain with the author(s) and / or copyright owner(s) of this work. Any use of the publication or parts of it other than authorised under article $25 \mathrm{fa}$ of the Dutch Copyright act is prohibited. Wageningen University \& Research and the author(s) of this publication shall not be held responsible or liable for any damages resulting from your (re)use of this publication.

For questions regarding the public availability of this publication please contact openscience.library@wur.nl 


\title{
Field performance of different maize varieties in growth cores at natural and reduced mycorrhizal colonization: yield gains and possible fertilizer savings in relation to phosphorus application
}

\author{
Xin-Xin Wang • Wopke van der Werf • Yang Yu • Ellis \\ Hoffland • Gu Feng • Thomas W. Kuyper \\ Received: 13 July 2019/Accepted: 3 April 2020 / Published online: 24April 2020 \\ (C) Springer Nature Switzerland AG 2020
}

\begin{abstract}
Aims The benefits of arbuscular mycorrhizal fungi (AMF) on yield and phosphorus (P) uptake of crops have commonly been studied by inoculating a single mycorrhizal fungal species in pot experiments. Yet, how the native AMF community affects the performance of different maize varieties under field conditions remains obscure.

Methods In-growth cores with and without rotation were used in three soils that differed in $\mathrm{P}$ application to assess shoot biomass, $\mathrm{P}$ uptake, and mycorrhizal colonization of three maize varietal groups,
\end{abstract}

Responsible Editor: Hans Lambers.

Electronic supplementary material The online version of this article (https://doi.org/10.1007/s11104-020-04524-1) contains supplementary material, which is available to authorized users.

X.-X. Wang · G. Feng $(\bowtie)$

College of Resources and Environmental Sciences and Centre for Resources, Environment and Food Security, China Agricultural University, Beijing 100193, People's Republic of China

e-mail: fenggu@cau.edu.cn

X.-X. Wang

Mountain Area Research Institute, Agricultural University of Hebei, Baoding 071001, People's Republic of China

X.-X. Wang · E. Hoffland · T. W. Kuyper

Soil Biology Group, Wageningen University \& Research, Wageningen, The Netherlands

W. van der Werf · Y. Yu

Centre for Crop Systems Analysis, Wageningen University \& Research, Wageningen, The Netherlands encompassing four inbred lines, 12 hybrids, and four landraces.

Results Rotating cores drastically reduced mycorrhizal colonization, biomass and $\mathrm{P}$ uptake for each varietal group at every $\mathrm{P}$ level. Performance of plants at natural mycorrhizal colonization at $30 \mathrm{~kg} \mathrm{P} \mathrm{ha}^{-1}$ was equal to that of reduced-mycorrhizal plants at $60 \mathrm{~kg} \mathrm{P} \mathrm{ha}^{-1}$, suggesting the potential for adequate mycorrhizal management to save $\mathrm{P}$ fertilizer.

Conclusion There were no significant differences between varietal groups for mycorrhizal responsiveness, confirming that the ability to associate with and benefit from AMF has been maintained in modern breeding. Mycorrhizal plants both exhibited higher $\mathrm{P}$ acquisition efficiency and higher $\mathrm{P}$ use efficiency than reducedmycorrhizal plants. Disadvantages of in-growth cores should be duly considered.

Keywords Mycorrhizal colonization · Maize · Phosphorus · Genetic variation · In-growth cores · Crop · Landrace

\section{Introduction}

Arbuscular mycorrhizal fungi (AMF) play a major role in the acquisition of nutrients, especially phosphorus (P) (Smith and Read 2008). The majority of plant species including crop species are responsive to mycorrhizal symbiosis. The degree to which plants respond to the mycorrhizal symbiosis is a function of plant species, especially root traits; soil conditions, such as inherent 
fertility, $\mathrm{pH}$ and management; and AMF species. To generate agronomic benefits for maize (Zea mays L.) production, inoculation in field conditions has been proposed (Bender et al. 2019); however, their results showed that the abundance and composition of native mycorrhizal communities determined establishment success of the inoculant. Although conventional agricultural management can exert adverse effects on AM fungal communities (Helgason et al. 1998; Oehl et al. 2003), high diversity of AMF can still be found in agricultural fields (Hijri et al. 2006; Sasvari et al. 2011). Thus, using the native AMF community to enhance mycorrhizal benefit for crops could be an alternative besides inoculating non-native mycorrhizal strains (Chave et al. 2019). But it is a prerequisite to understand how the native AMF community affects the performance of different crop species and varieties under field conditions.

Responsiveness, the relative or absolute increase in biomass or yield or nutrient content of a mycorrhizal plant compared to a non-mycorrhizal plant (Janos 2007), is therefore not a unique plant trait, but is determined by the tripartite interaction plant $\times \mathrm{AMF} \times$ environment, including soil management. As an alternative to this metric of responsiveness, defined as the yield difference at the same level of nutrient application, we can also express mycorrhizal benefit in terms of nutrients saved, that is differences in fertilizer application at the same level of plant biomass, as this metric could be important for expressing mycorrhizal benefits during ecological intensification of agriculture.

There is large variation in responsiveness both between and within plant species (Tawaraya 2003). Intraspecific (genetic) variation in responsiveness has been demonstrated for wild plants and major crops, such as the main cereals (wheat, barley, maize and rice), legumes, tomato, onion and cassava (Baon et al. 1993; Galván et al. 2011; Gao et al. 2007; Hajiboland et al. 2010; Hetrick et al. 1996; Kaeppler et al. 2000; Sieverding and Toro 1988; Wilson and Hartnett 1998). Kaeppler et al. (2000) compared 28 inbred lines of maize for mycorrhizal responsiveness in a low-P and a high-P soil and concluded that there was considerable genetic variation for mycorrhizal responsiveness in low-P soils.

Experiments to evaluate how plants respond to AMF are commonly executed under controlled conditions by comparing the growth of plants without mycorrhiza, after soil fumigation, pasteurization or sterilization, and with mycorrhiza, which is added by the investigator, together with the AMF-associated soil microbiota through a microbial wash. The source of mycorrhizal inoculum is often a specific fungal species, with which the plant may or may not be associated in the field (Klironomos 2003). For practical reasons such experiments are usually executed in pots in the greenhouse. Interpretation of the outcome of such experiments poses a number of challenges. First, comparison with a non-mycorrhizal plant may be problematic, considering that plant individuals without mycorrhiza are very seldom, if ever, found in the field. Second, species selection of AMF by the researcher does not necessarily reflect the selectivity that plants display in the field. Finally, greenhouse conditions can pose problems with light availability, pot size and with sterilization of soils (Poorter et al. 2016).

Such challenges are overcome in field studies in which the mycorrhizal effects on plant performance are studied with the natural AMF community; however, field experiments introduce their own constraints. Plenchette et al. (1983) assessed plant response to a mycorrhizal community in the field by fumigating soils and comparing non-inoculated, non-mycorrhizal and inoculated, mycorrhizal plants. This methodology could generate problems because of effects of fumigation on non-target organisms. It also does not address the issue that plants without mycorrhiza are very seldom, if ever, found in the field. Therefore a more realistic alternative could be to assess mycorrhizal responsiveness in the field through comparing plants with lower levels of mycorrhizal colonization with plants with higher colonization levels. Creating different colonization levels in the field can be achieved by inoculum addition to the mycorrhizal treatment, but this practice gives very variable results (Lekberg and Koide 2005). Differences in colonization can also be established by reducing mycorrhizal fungal abundance by solarization, bare fallow or the use of non-mycorrhizal plants like members of the Brassicaceae as a previous crop. However, these treatments could have impacts on other soil properties as well. Currently researchers prefer to grow plants in cores with sterilized soil inside, surrounded by a nylon mesh that allows hyphae to enter the core but does not allow the roots to go out (Johnson et al. 2001, 2002; Zhang et al. 2012). Rotating these cores damages the external mycelium and hence reduces mycorrhizal colonization and functioning (Johnson et al. 2001) without affecting roots or other soil properties (Leifheit et al. 2014). Liu et al. (2016) used in-growth cores to study how the indigenous mycorrhizal community increased salt 
tolerance of crop seedlings, demonstrating that ingrowth cores can be used for plants with greater biomass than grass plants.

Maize is a worldwide major crop. Thousands of varieties have been bred, and these can be grouped in three broad categories: landraces, inbred lines, and hybrids. Landraces are genotype mixtures that have been maintained under practical farming conditions by natural crossing. Inbred lines are developed by selfing in subsequent generations until a homozygous genotype is achieved; these lines are used by plant breeders to produce hybrids. Hybrids are commercial varieties that are produced by crossing two inbred lines. Commercial plant breeding takes place under nutrient-rich conditions and it has been suggested that such conditions may inadvertently select against the ability of modern varieties to benefit from mycorrhizal symbiosis in some crops (Gosling et al. 2006; Ryan and Graham 2002; Tawaraya et al. 2001). Breeding may also have affected the extent of mycorrhizal colonization. In a comparison of mycorrhizal colonization of 141 inbred lines, 38 hybrids, and 76 landraces of maize, modern hybrids showed significantly greater colonization than inbred lines and older landraces (An et al. 2010). However, variation in maize growth and $\mathrm{P}$ uptake by field mycorrhizal communities among these three maize groups has not been studied.

Here, we tested how 20 maize varieties (four landraces, 12 hybrids, and four inbred lines) respond to native AMF communities at three levels of $\mathrm{P}$ fertilizer in the field, using in-growth cores. We made measurements in three adjacent fields with a different history of P-fertilizer input but otherwise the same soil properties. We had three questions to investigate: 1) what is the magnitude of maize shoot biomass, $\mathrm{P}$ content and mycorrhizal root colonization as affected by three different $\mathrm{P}$ availability levels under natural and reduced mycorrhizal colonization? 2) how is the magnitude affected by the type of variety, landrace, inbred line or hybrid? 3) to what extent could differential performance between plants with natural and reduced levels of root colonization be translated into potential $\mathrm{P}$ fertilizer savings?

\section{Materials and methods}

Soils

A long-term P-fertilizer trial was conducted at Changping long-term Fertilizer Station of China
Agricultural University, Beijing $\left(40^{\circ} 05^{\prime} 32^{\prime \prime} \mathrm{N}, 116^{\circ} 20^{\prime}\right.$ $\left.41^{\prime \prime} \mathrm{E}\right)$. In three adjacent fields with the same soil, three fertilizer regimes were applied $(0,30$ and $60 \mathrm{~kg} P$ ha $^{-1} \mathrm{yr}^{-1}$; denoted as $\mathrm{P}_{0}, \mathrm{P}_{30}$ and $\left.\mathrm{P}_{60}\right)$. Maize has been continuously cultivated in each field for 16 years (19922008). Except for differences in $P$ availability (Olsen-P), there were no significant differences in soil properties among the fields ( $\mathrm{P}$ treatments) (more information shown in Table 1). Therefore, we refer to three P levels and three fields interchangeably; and treat soil P level as a factor in our analyses. All fields received $\mathrm{N}$ as urea at a rate of $135 \mathrm{~kg} \mathrm{~N} \mathrm{ha}^{-1} \mathrm{yr}^{-1}$ and $\mathrm{K}$ at a rate of $225 \mathrm{~kg} \mathrm{ha}^{-1} \mathrm{yr}^{-1}$. Fertilizer was applied on May 3rd, 2009. Soils in the three fields were collected separately on May 5th, 2009, passed through a 2-mm sieve and sterilized by radiation with ${ }^{60} \mathrm{Co} \gamma$-ray at $10 \mathrm{kGy}$. Sterilized soils were used to fill cores for each $\mathrm{P}$ treatment.

In-growth cores

We used in-growth cores as described by Liu et al. (2016) in this experiment. The cores were made from polyvinylchloride (PVC) water pipes with $5 \mathrm{~cm}$ inner diameter and $25 \mathrm{~cm}$ length. Each core had two 'windows' of $12 \mathrm{~cm}$ length $\times 4 \mathrm{~cm}$ width, placed symmetrically on two sides of the core, and sealed with $30 \mu$ mylon mesh through which hyphae but not roots could pass. The base of each core was sealed by a circular PVC board (see Fig. $\mathrm{S} 1)$. The cores were inserted till a depth of $22 \mathrm{~cm}$, and the upper $3 \mathrm{~cm}$ were above the soil. Cores were filled (up to the soil - atmosphere layer, hence over a length of $22 \mathrm{~cm}$ ) with $240 \mathrm{~g}$ sterilized soil from that same field. Cores of the rotation treatment were rotated about $45^{\circ}$ twice weekly to break the hyphae penetrating the core.

\section{Test plants}

Twenty maize varieties were used: Jinhuanghou (JHH), Baimaya (BMY), Huangmaya (HMY) and Yinglizi (YLZ) are landraces bred in the 1950s; Zhongdan2 (ZD2), Huang417 (H417), Yedan13 (YD13), Nongda108 (ND108), Zhongdan958 (ZD958), Junddan20 (JD20), Xiuqing13 (XQ13), Liyu13 (LY13), Liyu16 (LY16), Jinhai5 (JH5), Xianyu335 (XY335) and 32D22 are modern hybrids; 181, 197, Wu312 (W312) and 478 are inbred lines.

In each core, two maize seeds (surface-sterilized for $10 \mathrm{~min}$ in $10 \% \mathrm{H}_{2} \mathrm{O}_{2}$ followed by $3 \mathrm{~min}$ in $70 \%$ ethanol) were sown on May 11st, 2009; they were thinned to one 
Table 1 Soil chemical properties of experimental fields

\begin{tabular}{lllll}
\hline Soil treatment & $\mathrm{pH}$ & Total $\mathrm{N}\left(\mathrm{g} \mathrm{kg}^{-1}\right)$ & Olsen-P $\left(\mathrm{mg} \mathrm{kg}^{-1}\right)$ & Organic matter $\left(\mathrm{g} \mathrm{kg}^{-1}\right)$ \\
\hline $\mathrm{P}_{0}$ & 7.81 & 0.87 & 2.9 & 17.8 \\
$\mathrm{P}_{30}$ & 7.97 & 0.70 & 6.4 & 15.4 \\
$\mathrm{P}_{60}$ & 7.79 & 0.68 & 15.0 & 17.2 \\
\hline
\end{tabular}

plant per core after germination. During the experiment, tap water was added every day, except for rainy days. In May, the daytime temperature ranged from 14 to $26^{\circ} \mathrm{C}$ and in June from 20 to $30{ }^{\circ} \mathrm{C}$. Rainfall was $30 \mathrm{~mm}$ in May and $50 \mathrm{~mm}$ in June. The plants were harvested on June 26th, 2009, i.e. 45 days after sowing. Planting distance, hence distance between cores, was $30 \mathrm{~cm}$.

Experimental design

We installed in-growth cores in each of the three fields on May 9th, 2009. Rotated and non-rotated cores with different maize varieties were placed in a $5 \mathrm{~m} \times 5 \mathrm{~m}$ section of each field. Three factors were tested: (1) Rotation (without or with rotation); (2) Variety (20 maize varieties belonging to three groups); (3) P levels $\left(0,30\right.$ and $\left.60 \mathrm{~kg} \mathrm{P} \mathrm{ha}^{-1}\right)$. We used complete randomization with five replicate cores for each combination, resulting in 200 cores per field.

Harvest and sample analysis

Plants were harvested 6.5 weeks after sowing. At harvest, shoots (aboveground material containing both stems and leaves) and roots were separately collected. Shoots were oven-dried at $70{ }^{\circ} \mathrm{C}$ for 3 days, weighed and ground to fine powder. After digestion for $2 \mathrm{~h}$ at $360{ }^{\circ} \mathrm{C}$ in a mixture of $\mathrm{H}_{2} \mathrm{SO}_{4}$ and $\mathrm{H}_{2} \mathrm{O}_{2}$ (Bao 2000), shoot $\mathrm{P}$ concentration was determined by the molybdovanado-phosphate method (Kitson and Mellon 1944). Roots were washed with deionized water, and preserved at $-20{ }^{\circ} \mathrm{C}$. Frozen roots were cut into $1-\mathrm{cm}$ segments and thoroughly mixed. A 0.5 -g subsample was cleared with $10 \%(w / v) \mathrm{KOH}$ at $90{ }^{\circ} \mathrm{C}$ for $2 \mathrm{~h}$ and stained with trypan blue for quantification of mycorrhizal colonization (Trouvelot et al. 1986).

Data analysis

A nested three-way ANOVA was used to analyse, the effect of Rotation $(R)$, Variety groups $(G)$, and Varieties
(V) within variety group, and $\mathrm{P}$ level on mycorrhizal colonization, plant biomass, shoot $\mathrm{P}$ concentration and $\mathrm{P}$ content. Significant differences between rotated and non-rotated cores and between maize variety groups were tested with Tukey's Honestly Significant Differences test at the 5\% level. Linear regression was used to model the relationship between shoot $\mathrm{P}$ content $(P)$ and shoot biomass $(B)$ for each variety group with natural or with reduced mycorrhizal colonization. The analysis was done with Stats package in R ( $\mathrm{R}$ core team 2016). The final fitted model was:

$$
\begin{aligned}
B_{i}= & \beta_{o}+\beta_{1} * \ln \left(P_{i}\right)+\beta_{2} * G_{2 i}+\beta_{3} * G_{3 i}+\beta_{4} * R_{i} \\
& +\beta_{5} * \ln \left(P_{i}\right) * G_{2 i}+\beta_{6} * \ln \left(P_{i}\right) * G_{3 i} \\
& +\beta_{7} * \ln \left(P_{i}\right) * R_{i}
\end{aligned}
$$

where $B_{i}$ is the biomass (g plant ${ }^{-1}$ ) of object (= plant) $i$; $P_{i}$ is the shoot $\mathrm{P}$ content (mg plant ${ }^{-1}$ ) of object $i ; G_{. i}$ are indicator variables denoting the variety group (categorical; 3 levels) of object $i$ : $G_{2 i}$ : Hybrids; $G_{3 i}$ : Inbred lines; $R_{i}$ is the rotation treatment of object $i$ ( 0 : no rotation or 1 : rotation); $\ln \left(P_{i}\right) * G_{i}$ represents the interaction between $\mathrm{P}$ level and variety group; $\beta_{0}$ is the intercept, $\beta_{1}$ represents the slope of the relationship between $\ln \left(P_{i}\right)$ and $B_{i}$ for the reference variety group (landraces), $\beta_{2}$ represents a difference in intercept between hybrids and landraces while $\beta_{3}$ represents a difference in intercept between inbred lines and landraces. $\beta_{4}$ denotes the effect of rotation $\left(\right.$ reference $=$ no rotation). $\beta_{5}$ denotes the difference in slope of $B$ versus $\ln (P)$ between hybrids and landraces while $\beta_{6}$ denotes the difference in slope between inbred lines and landraces. $\beta_{7}$ denotes the effect of rotation on the slope of the relationship between $B$ and $\ln (P)$. This model was chosen after backwards regression with a full model, when it was found that the other interactions $(\mathrm{G} * R$ and $\ln (P) * G * R)$ were not significant. While the regression is linear, the fitted relationship between the response variable and $\mathrm{P}$ content is non-linear, because the latter was entered into the model after logarithmic transformation. Model residuals 
were inspected for normality, homoscedasticity, and outliers using plot (model) statement in R. No departures from the assumptions were found.

\section{Results}

All 20 maize varieties were colonized by AMF at each P level. Rotation of the cores had the intended effect of reducing mycorrhizal colonization, from $45 \pm 1.3 \%$ to $7.1 \pm 0.3 \%$ in $\mathrm{P}_{0}$ (data are presented as mean $\pm \mathrm{SE}$ in the whole paper), from $45 \pm 1.2 \%$ to $7.3 \pm 0.3 \%$ in $\mathrm{P}_{30}$, and from $33 \pm 1.1 \%$ to $6.3 \pm 0.4 \%$ in $\mathrm{P}_{60}$ (Table 2 and $\mathrm{S} 1$; Fig. 1). In non-rotated treatments, plants at $P_{60}$ had the lowest mycorrhizal colonization $(33 \pm 1.1 \%)$, significantly lower than at $\mathrm{P}_{0}$ and $\mathrm{P}_{30}$ (Table 2). With rotation, mycorrhizal colonization was 6-7\% across all $\mathrm{P}$ levels (Table 2). There were no significant differences in mycorrhizal colonization among the three variety groups, but there was substantial variation in colonization within each group (Table 2; Tables S1 and S2).

Rotation significantly affected shoot biomass (Fig. 2a and Fig. S2). Plants in rotated cores had a significantly lower shoot biomass than plants without rotation (1.18 \pm 0.03 vs $1.55 \pm 0.04$ g plant $^{-1}$ ) (Table 2). Regardless of the rotation treatment, shoot biomass was highest at $\mathrm{P}_{60}$ and lowest at $\mathrm{P}_{0}$ (Table 1 ). Maize variety groups differed significantly in shoot biomass (Table S1). Averaged across rotation and $\mathrm{P}$ levels, hybrids had the highest shoot biomass $\left(1.43 \pm 0.03 \mathrm{~g} \mathrm{plant}^{-1}\right)$, significantly higher than landraces $\left(1.31 \pm 0.03 \mathrm{~g} \mathrm{plant}^{-1}\right)$, which was significantly higher than inbred lines $\left(1.23 \pm 0.04 \mathrm{~g} \mathrm{plant}^{-1}\right)$.

Shoot biomass of plants with reduced colonization at $\mathrm{P}_{0}$ responded to $\mathrm{P}$ addition (to $\mathrm{P}_{30}$ ) more than to $\mathrm{AMF}$ (from rotation to non-rotation), whereas at $\mathrm{P}_{30}$ shoot biomass responded similarly to doubling of $\mathrm{P}$ (to $\mathrm{P}_{60}$ ) and to AMF (from rotation to non-rotation) (Fig. 2a). Shoot biomass was significantly lower at $\mathrm{P}_{0}$ without rotation than at $\mathrm{P}_{30}$ with rotation. This conclusion is valid for the three maize variety groups $(0.74 \pm 0.02 \mathrm{vs}$ $1.27 \pm 0.03 \mathrm{~g} \mathrm{plant}^{-1}$ ) and for each maize group separately (landraces: $0.79 \pm 0.03$ vs $1.13 \pm 0.05 \mathrm{~g}$ plant $^{-1}$; hybrids: $0.76 \pm 0.02$ vs $1.34 \pm 0.03 \mathrm{~g} \mathrm{plant}^{-1}$; inbred lines: $0.62 \pm 0.03$ vs $1.20 \pm 0.07 \mathrm{~g} \mathrm{plant}^{-1}$ ) (Table 2 and Fig. 2a). Shoot biomass at $\mathrm{P}_{30}$ without rotation was not significantly different from that at $\mathrm{P}_{60}$ with rotation, indicating that under these conditions proper mycorrhizal management can result in substantial lowering of $\mathrm{P}$ application $\left(1.75 \pm 0.04\right.$ at $\mathrm{P}_{30}$ without rotation vs $1.78 \pm 0.04 \mathrm{~g} \mathrm{plant}^{-1}$ at $\mathrm{P}_{60}$ with rotation). This result holds for each of the variety groups (landraces: $1.69 \pm 0.08$ vs $1.67 \pm 0.08 \mathrm{~g} \mathrm{plant}^{-1}$; hybrids: $1.85 \pm 0.04$ vs $1.89 \pm 0.04$ g plant $^{-1}$; inbred lines: 1.50 \pm 0.04 vs $1.58 \pm 0.09$ g plant $^{-1}$ ) (Table 2 and Fig. 2a).

Landraces performed better than hybrids at low P, but hybrids outperformed landraces at high P. Averaged across rotation levels, landraces had the highest biomass at $\mathrm{P}_{0}, 0.70 \pm 0.02 \mathrm{~g} \mathrm{plant}^{-1}$, followed by hybrids $(0.62 \pm$ 0.02 g plant $\left.^{-1}\right)$, and inbred lines $\left(0.54 \pm 0.02\right.$ g plant $\left.^{-1}\right)$; at $\mathrm{P}_{60}$, hybrids had a significantly higher shoot biomass $\left(2.07 \pm 0.04 \mathrm{~g} \mathrm{plant}^{-1}\right)$ than landraces $(1.83 \pm 0.07 \mathrm{~g}$ plant $\left.^{-1}\right)$ and inbred lines $\left(1.79 \pm 0.07 \mathrm{~g} \mathrm{plant}^{-1}\right)$ (Table 2).

Shoot $\mathrm{P}$ content at $\mathrm{P}_{30}$ without rotation was not significantly different from that at $\mathrm{P}_{60}$ with rotation. This was true on average over the variety groups $(3.08 \pm 0.10 \mathrm{vs}$ $3.11 \pm 0.12 \mathrm{mg} \mathrm{P}$ plant $^{-1}$ ) and for each maize group separately (landraces: $2.95 \pm 0.24$ vs $2.93 \pm 0.32 \mathrm{mg} P$ plant $^{-1}$; hybrids: $3.21 \pm 0.14$ vs $3.05 \pm 0.11 \mathrm{mg} \mathrm{P}$ plant $^{-1}$; inbred lines: $2.81 \pm 0.22$ vs $3.48 \pm 0.35 \mathrm{mg} P$ plant ${ }^{-1}$ ). Shoot $\mathrm{P}$ content at $\mathrm{P}_{0}$ without rotation was significantly lower than that at $\mathrm{P}_{30}$ with rotation (Table 2; Fig. 2b). Because plants in non-rotated cores had higher $\mathrm{P}$ concentrations than plants in rotated cores (with strongly reduced root colonization), the effect of mycorrhiza on P content was larger than that on biomass. Among the three variety groups, inbred lines had the highest shoot P concentration (Table 2; Fig. S3).

The ANOVA and the values of the various coefficients of the linear regression between biomass and natural logarithm of P content are given in Tables 3 and 4 . Biomass increased significantly with shoot $\mathrm{P}$ content for all maize varietal groups and was higher in the nonrotated than in the rotated cores (Fig. 3). There was no interaction between varietal groups and rotation treatment for slopes. The relationship between biomass and shoot $\mathrm{P}$ content was significantly stronger for non-rotation treatments than for rotation treatments (Eq. 1: $\beta_{7}=0.13$, $P<0.001$; Table 3), indicating that, at the same $\mathrm{P}$ content (and hence $\mathrm{P}$ uptake), mycorrhizal plants showed higher $\mathrm{P}$ use efficiency (and less luxury P uptake) than plants with reduced colonization. Inbred lines had the lowest $\mathrm{P}$ use efficiency (or highest luxury P uptake). The slope between shoot biomass and $\ln (\mathrm{P}$ content $)$ was significantly greater for landraces $\left(\beta_{6}=-0.094, P=0.006\right.$; Table 3$)$ and hybrids $\left(\beta_{5}+\beta_{6}=-0.132, P<0.001\right.$; Table 3$)$ than for inbred lines while there was no significant difference of biomass - shoot $\mathrm{P}$ content relationship between landraces and hybrids $\left(\beta_{5}=-0.038, P=0.21\right.$; Table 3$)$. 
.

学 $0^{\circ}$

๓

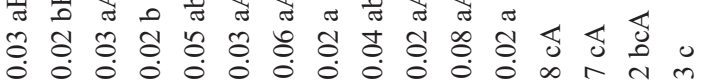

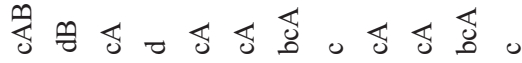

물

党

d o t

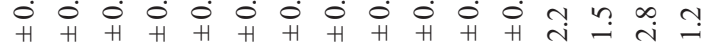

舟

H $\begin{aligned} & H \\ & 1\end{aligned}$

శ.

घี

กิ

फ़े

$\infty$

争

ङ

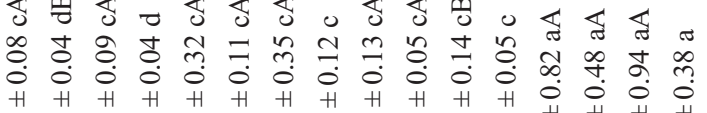

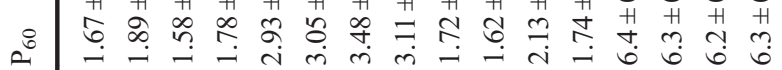

.

言

בี

。ำ $-$

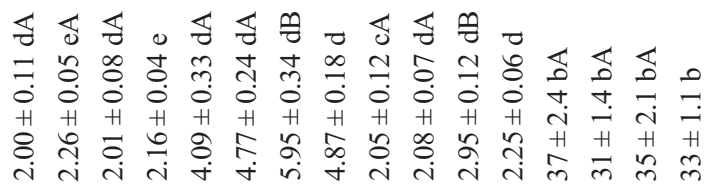

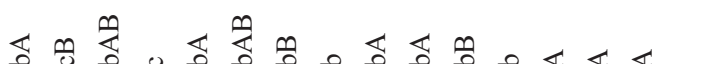

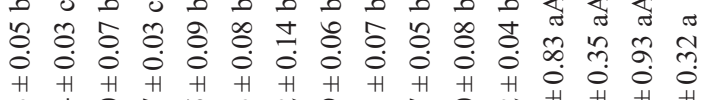

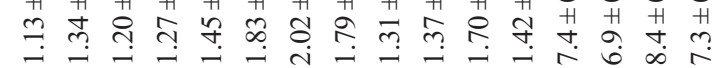

के

氖

(a)

$m \ll \ll \infty \ll \ll<थ$

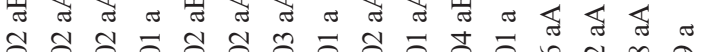

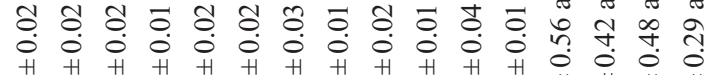

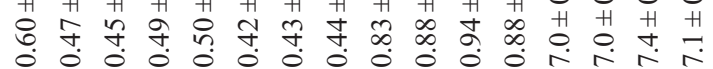


Fig. 1 Mycorrhizal colonization (\%) of three maize variety groups, landraces, hybrids and inbred lines, depending on $\mathrm{P}$ supply under rotated $(+\mathrm{R})$ or non-rotated conditions $(-\mathrm{R})$. Values are means $\pm \mathrm{SE}$

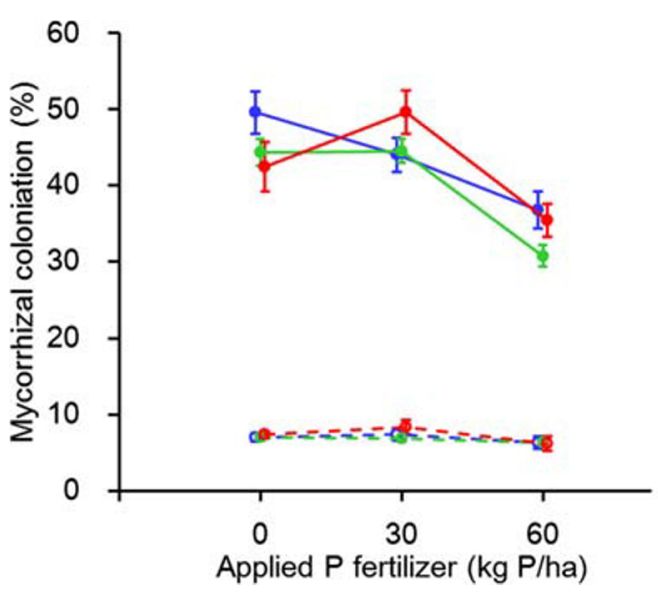

- o- Landraces+R

$\rightarrow$ Landraces-R

- - - Hybrids $+R$

$\longrightarrow$ Hybrids-R

- - - Inbred lines+R

$\leftrightarrow$ Inbred lines- $R$

\section{Discussion}

Mycorrhizal benefits and potential phosphorus savings

Our study showed that natural AMF communities under undisturbed conditions have a positive effect on biomass and $\mathrm{P}$ content of maize. Reducing mycorrhizal colonization, in our case as a consequence of rotation, reduced plant performance. Consequently, at the same $\mathrm{P}$ fertilizer application, mycorrhizal plants were larger than plants where the rotation of the cores drastically reduced mycorrhizal colonization. Comparable plant biomass and $\mathrm{P}$ content (and hence P uptake) were achieved at lower P fertilizer levels when plants were mycorrhizal. This indicates that enhanced nutrient acquisition efficiency through AMF may play a substantial role in saving P fertilizer, at least in fields with a substantial legacy of previous $\mathrm{P}$ fertilizer application.

In this study, shoot biomass at $\mathrm{P}_{30}$ without rotation was not significantly different from that at $\mathrm{P}_{60}$ with rotation (Fig. 2a), suggesting options for $P$ fertilizer savings with appropriate management that avoids reductions in mycorrhizal colonization. Recent estimates by FAO (2015) indicate a global $\mathrm{P}$ use of around 10 million ton $\mathrm{P}$ at an average prices of $\$ 300$ per ton. Thus, AMF provide major contributions to ecosystem services (Gianinazzi et al. 2010) that could also be valued from a monetary perspective.

Genetic variation between varietal groups

in mycorrhizal colonization and benefit

No major differences in mycorrhizal colonization were found between three maize variety groups (Table 2), confirming that the ability to associate with AMF was maintained in maize breeding (An et al. 2010). Hybrids yielded more than landraces at $\mathrm{P}_{60}$, whereas landraces yielded more than hybrids at $\mathrm{P}_{0}$. There were no significant differences in biomass enhancement by AMF between hybrids and landraces (Figs. 2 and 3), indicating that also the ability to benefit from the association with AMF was maintained in maize breeding. However, large variation in mycorrhizal colonization and benefit within the variety groups suggests possibilities for targeted breeding efforts.

Hetrick et al. (1992) claimed that modern wheat varieties benefitted less from mycorrhizal symbiosis than old varieties, which would imply that modern breeding practices have in fact selected against mycorrhizal benefit. Our data do not confirm this claim for modern maize varieties. Our results are consistent with the study by Wright et al. (2005) who found that a European maize hybrid had not lost the ability to benefit from AMF compared with an African landrace, particularly at low P supply; and with the study of Chu et al. (2013) who concluded that maize breeding did not select against the ability to benefit from mycorrhiza under low-P conditions. Modern crop varieties tend to be selected for high $\mathrm{P}$ acquisition at high $\mathrm{P}$ supply, and differential responses of varietal groups at $\mathrm{P}_{0}$ and $\mathrm{P}_{60}$ are consistent with this selection process (Table 2). Our results imply that modern breeding does not affect the mycorrhizal responsiveness but the responsiveness to $\mathrm{P}$ supply of modern crops varieties.

We modelled the relation between shoot biomass and the natural logarithm of shoot P content (Fig. 3) and noted a higher slope for mycorrhizal plants than for reduced-mycorrhizal plants, and a higher slope for 
Fig. 2 Shoot biomass (g plant ${ }^{-1}$; $\mathbf{a}$ and shoot $\mathrm{P}$ content $\left(\mathrm{mg}\right.$ plant $^{-1}$; b of three maize variety groups, landraces, hybrids and inbred lines, depending on $\mathrm{P}$ supply under rotated $(+\mathrm{R})$ or non-rotated conditions $(-\mathrm{R})$. Values are means $\pm \mathrm{SE}$

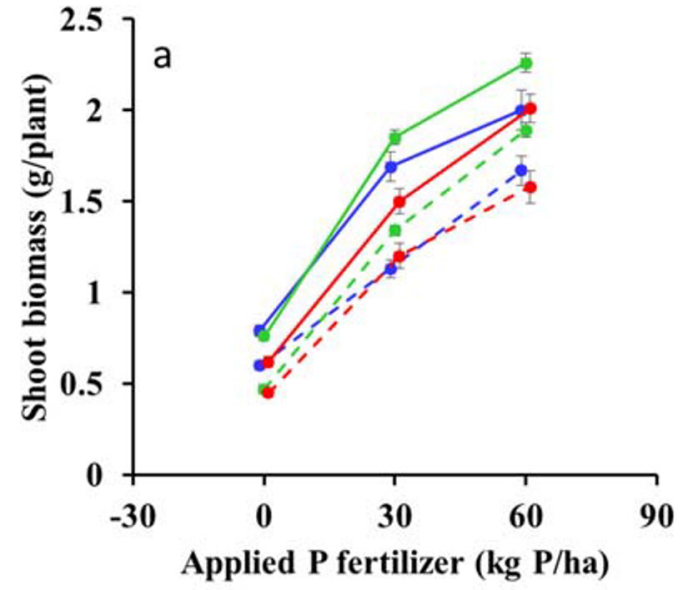

- - Landraces $+\mathbf{R}$ $\rightarrow$ Landraces- $R$ - - Hybrids $+\mathbf{R}$ $\multimap$ Hybrids-R - - Inbred lines $+\mathbf{R}$ $\rightarrow-$ Inbred lines-R

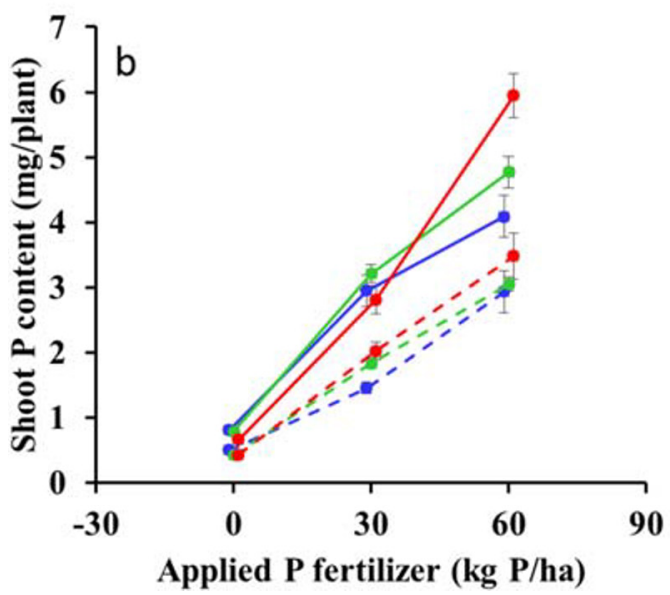

landraces and hybrids than for inbred lines. This slope slope $=0$ indicating complete luxury uptake, where adcan be seen as a proxy for nutrient use efficiency, with a ditional $\mathrm{P}$ acquired is not converted into biomass, and a

Table 3 Full ANOVA table of model 1: $B_{i}=\beta_{o}+\beta_{1} * \ln \left(P_{i}\right)+\beta_{2} * G_{2 i}+\beta_{3} * G_{3 i}+\beta_{4} * R_{i}+\beta_{5} * \ln \left(P_{i}\right) * G_{2 i}+\beta_{6} * \ln \left(P_{i}\right) * G_{3 i}+\beta_{7} *$ $\ln \left(P_{i}\right) * R_{i}$

\begin{tabular}{lllllc}
\hline & Df & Sum Square & Mean Square & F-value & $P$ value \\
\hline Groups (G) & 2 & 4.009 & 2.004 & 37.6 & $4.24 \mathrm{E}-16$ \\
Ln(P) & 1 & 227.282 & 227.282 & 4263 & $2.20 \mathrm{E}-16$ \\
Rotation (R) & 1 & 0.034 & 0.034 & 0.638 & 0.4247 \\
G:Ln(P) & 2 & 1.276 & 0.638 & 12.0 & $8.05 \mathrm{E}-06$ \\
Ln(P):R & 1 & 1.811 & 1.811 & 34.0 & $9.23 \mathrm{E}-09$ \\
Residuals & 592 & 31.559 & 0.053 & &
\end{tabular}

In the model, $B_{i}$ is the biomass (g plant ${ }^{-1}$ ) of object (= plant) $i ; P_{i}$ is the shoot $\mathrm{P}$ content $\left(\mathrm{mg}_{\text {plant }}{ }^{-1}\right.$ ) of object $i$; $G_{. i}$ are indicator variables denoting the variety group (categorical; 3 levels) of object $i$ : $G_{2 i}$ : Hybrids; $G_{3 i}$ : Inbred lines; $R_{i}$ is the rotation treatment of object $i$ ( 0 : no rotation or 1: rotation); $\ln \left(P_{i}\right) * G_{i}$ represents the interaction between P level and variety group; $\beta_{0}$ is the intercept, $\beta_{1}$ represents the slope of the relationship between $\ln \left(P_{i}\right)$ and $B_{i}$ for the reference variety group (landraces), $\beta_{2}$ represents a difference in intercept between hybrids and landraces while $\beta_{3}$ represents a difference in intercept between inbred lines and landraces. $\beta_{4}$ denotes the effect of rotation (reference $=$ no rotation). $\beta_{5}$ denotes the difference in slope of $B$ versus $\ln (P)$ between hybrids and landraces while $\beta_{6}$ denotes the difference in slope between inbred lines and landraces. $\beta_{7}$ denotes the effect of rotation on the slope of the relationship between $B$ and $\ln (P)$ 
Table 4 Estimated coefficients of model 1: $B_{i}=\beta_{o}+\beta_{1} * \ln \left(P_{i}\right)+$ $\beta_{2} * G_{2 i}+\beta_{3} * G_{3 i}+\beta_{4} * R_{i}+\beta_{5} * \ln \left(P_{i}\right) * G_{2 i}+\beta_{6} * \ln \left(P_{i}\right) *$ $G_{3 i}+\beta_{7} * \ln \left(P_{i}\right) * R_{i}$

\begin{tabular}{lllll}
\hline Coefficient & Estimate & SE & t-value & P value \\
\hline$\beta_{0}$ & 1.01 & 0.026 & 39.35 & $2 \mathrm{E}-16$ \\
$\beta_{1}$ & 0.62 & 0.029 & 21.50 & $2 \mathrm{E}-16$ \\
$\beta_{2}$ & 0.062 & 0.028 & 2.22 & 0.026 \\
$\beta_{3}$ & -0.083 & 0.034 & -2.44 & 0.015 \\
$\beta_{4}$ & -0.053 & 0.023 & -2.31 & 0.020 \\
$\beta_{5}$ & 0.038 & 0.030 & 1.27 & 0.21 \\
$\beta_{6}$ & -0.094 & 0.034 & -2.76 & 0.006 \\
$\beta_{7}$ & 0.13 & 0.022 & 5.83 & $9.23 \mathrm{E}-09$ \\
\hline
\end{tabular}

In the model, $B_{i}$ is the biomass ( g plant $^{-1}$ ) of object (= plant) $i ; P_{i}$ is the shoot $\mathrm{P}$ content (mg plant $\left.{ }^{-1}\right)$ of object $i ; G_{. i}$ are indicator variables denoting the variety group (categorical; 3 levels) of object $i$ : $G_{2 i}$ : Hybrids; $G_{3 i}$ : Inbred lines; $R_{i}$ is the rotation treatment of object $i$ ( 0 : no rotation or 1: rotation); $\ln \left(P_{i}\right) * G_{i}$ represents the interaction between $\mathrm{P}$ level and variety group; $\beta_{0}$ is the intercept, $\beta_{1}$ represents the slope of the relationship between $\ln \left(P_{i}\right)$ and $B_{i}$ for the reference variety group (landraces), $\beta_{2}$ represents a difference in intercept between hybrids and landraces while $\beta_{3}$ represents a difference in intercept between inbred lines and landraces. $\beta_{4}$ denotes the effect of rotation (reference $=$ no rotation). $\beta_{5}$ denotes the difference in slope of $B$ versus $\ln (P)$ between hybrids and landraces while $\beta_{6}$ denotes the difference in slope between inbred lines and landraces. $\beta_{7}$ denotes the effect of rotation on the slope of the relationship between $B$ and $\ln (P)$

positive slope indicating that additional $\mathrm{P}$ acquired is partly converted into biomass. A higher slope for mycorrhizal, compared to reduced-mycorrhizal plants indicates that the mycorrhizal symbiosis improves the plant's stoichiometric balance (Elser et al. 2010) and increases nutrient use efficiency, the ability to convert additional nutrients into biomass. This latter conclusion may seem at odds with earlier suggestions by Van der Heijden (2002), who referred to the intuitively paradoxical situation that mycorrhizal fungi increase nutrient acquisition efficiency, but reduce nutrient use efficiency, defined as the inverse of nutrient concentration. However, in this study plants of, sometimes very, different sizes were compared. In our study, at the same size, mycorrhizal plants had lower P concentrations and at the same P concentration, mycorrhizal plants produced more biomass. Physiological studies are recommended to understand the underlying basis for increased nutrient use efficiency of mycorrhizal plants (Cardoso et al. 2004). The significant differences in slope between on the one hand landraces and modern hybrids and on the other hand inbred lines (with a lower P use efficiency) indicates a genetic basis for this efficiency component, which equally merits further study.

The effects of $\mathrm{P}$ availabilities on different AMF communities and host preference

Different plant species are colonized by different AMF communities (Sanders 2003), and the same applies to different varieties of the same crop species (Oliveira et al. 2009; Sangabriel-Conde et al. 2015). In addition, available soil $\mathrm{P}$ plays a major role in determining the composition and abundance of native AMF communities (Bender et al. 2019). Effective mycorrhizal colonization (that is, when potentially achievable root colonization levels are reached) may influence the maize yield by modulating the capacity of different varieties to tolerate P deficiency (Bender et al. 2019; Oliveira et al. 2009). Preliminary investigations showed small differences in species richness between fields of $\mathrm{P}_{30}$ and $\mathrm{P}_{60}$ and also small differences in species composition among four varieties tested (data not shown), suggesting that it is abundance rather than species composition of AMF that drove the mycorrhizal responsiveness. Considering that mycorrhizal diversity was not very high in local farmlands (Wang et al. 2015), the small differences in AMF community differentiation both among maize varietal groups and among soils with different $\mathrm{P}$ availability may not be surprising. Our data confirm a previous study by Galván et al. (2009) who noted species-poor AMF communities in onion (Allium cepa $\mathrm{L}$.) fields in the Netherlands with small differences in those communities in fields were due to differences in P availability.

Strengths and limitations of in-growth cores for assessing mycorrhizal responsiveness in the field

Compared to the classical method with inoculated pots and sterilized, non-mycorrhizal controls, advantages and disadvantages of in-growth cores need to be addressed. With in-growth cores, it is impossible to have an absolute non-mycorrhizal control. Roots in rotated cores were also colonized, but to a much lower extent than roots in nonrotated cores. However, by not fully eliminating mycorrhizal colonization, we may have increased agroecological realism. Plant roots in our cores were limited to a smaller soil volume than they would normally exploit. Core size constrained plant biomass compared to plants that were growing outside cores: biomass of our plants was around $10 \%$ of biomass of freely growing 

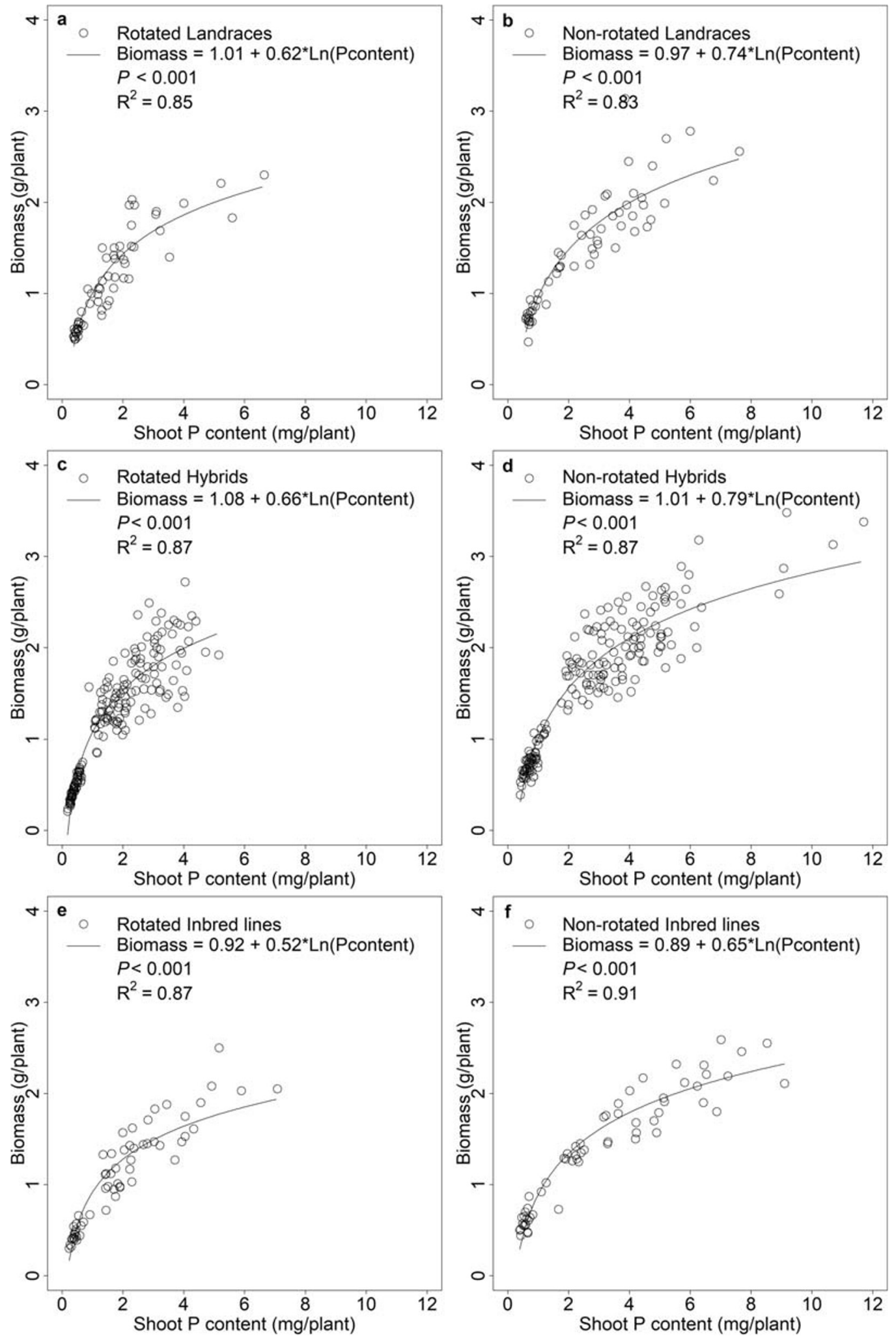
Fig. 3 Relationship between shoot $\mathrm{P}$ content and shoot biomass for different maize variety groups with and without core-rotation. $\mathrm{R}^{2}$ is calculated based on the predicted and observed values of each regression line, using the equation: $\mathrm{R}^{2}=1-\mathrm{SSE} / \mathrm{SST}$. SSE is the sum of squares of errors, $\operatorname{SSE}=\operatorname{SUM}\left(\mathrm{y}_{i}-\hat{\mathrm{y}}_{i}\right)^{\wedge}$, SST is the total sum of squares, $\mathrm{SST}=\operatorname{SUM}\left(\mathrm{y}_{i}-\right)^{\wedge} \cdot \hat{\mathrm{y}}_{i}$ is the predicted biomass with a given regression line, $\mathrm{P}$ content $\mathrm{t}_{i}$ and rotation treatment; $\mathrm{y}_{i}$ is the observed biomass at given $\mathrm{P}$ content ${ }_{i}$ and rotated treatment; is the mean of biomass of a given rotation treatment

plants. Our design could then overestimate the effect of AMF: the increase in soil volume that can be exploited by mycorrhizal plants in non-rotated cores is likely larger than under natural conditions. Moreover, although Leifheit et al. (2014) showed that regular rotation did not influence some soil parameters (e.g. water content, water-stable soil aggregates and carbon and nitrogen concentrations), core rotation inevitably could modify soil structure in the immediate vicinity of the cores, and cut not only AM fungal hyphae, but also solute bridges between the cores and the surrounding soil, by introducing air gaps. Core rotation may also cause a mechanical disturbance of the roots inside the cores. For future experiments, a larger core size is therefore recommended to gain a better understanding of mycorrhizal benefits and potential $\mathrm{P}$ fertilizer savings in the field. Two-walled cores, where outer cores remain static and inner cores be rotated regularly over the entire experiment, would probably be a better option to reduce biases brought by our in-growth core design.

Acknowledgments This study was financially supported by National Key R\&D Program of China (2017YFD0200200) and the National Natural Science Foundation of China (U1703232). We are grateful two anonymous reviewers for their critical comments on an earlier version of this manuscript.

\section{Compliance with ethical standards}

Conflict of interest The authors declare that they have no conflict of interest.

\section{References}

An GH, Kobayashi S, Enoki H, Sonobe K, Muraki M, Karasawa T, Ezawa T (2010) How does arbuscular mycorrhizal colonization vary with host plant genotype? An example based on maize (Zea mays) germplasms. Plant Soil 327:441-453
Bao SD (2000) Soil agrochemical analysis, 3rd edn. China Agriculture Press, Beijing, pp 1-495

Baon JB, Smith SE, Alston AM (1993) Mycorrhizal responses of barley cultivars differing in P-efficiency. Plant Soil 157:97105

Bender SF, Schlaeppi K, Held A, Van der Heijden MGA (2019) Establishment success and crop growth effects of an arbuscular mycorrhizal fungus inoculated into Swiss corn fields. Agric Ecosyst Environ 273:13-24

Cardoso IM, Boddington CL, Janssen BH, Oenema O, Kuyper TW (2004) Double pot and double compartment: integrating two approaches to study nutrient uptake by arbuscular mycorrhizal fungi. Plant Soil 260:301-310

Chave M, Angeon V, Paut R, Collombet R, Tchamitchian M (2019) Codesigning biodiversity-based agrosystems promotes alternatives to mycorrhizal inoculants. Agron Sustain Dev 39:48

Chu Q, Wang XX, Yang Y, Chen FJ, Zhang FS, Feng G (2013) Mycorrhizal responsiveness of maize (Zea mays L.) genotypes as related to releasing date and available $\mathrm{P}$ content in soil. Mycorrhiza 23:497-505

Elser JJ, Fagan WF, Kerkhoff AJ, Swenson NG, Enquist BJ (2010) Biological stoichiometry of plant production: metabolism, scaling and ecological response to global change. New Phytol 186:593-608

FAO (2015) World fertilizer trends and outlook. FAO, Rome, pp $1-53$

Galván GA, Parádi I, Burger K, Baar J, Kuyper TW, Scholten OE, Kik C (2009) Molecular diversity of arbuscular mycorrhizal fungi in onion roots from organic and conventional farming systems in the Netherlands. Mycorrhiza 19:317-328

Galván GA, Kuyper TW, Burger K, Keizer LCP, Hoekstra RF, Kik C, Scholten OE (2011) Genetic analysis of the interaction between Allium species and arbuscular mycorrhizal fungi. Theor Appl Genet 122:947-960

Gao XP, Kuyper TW, Zou CQ, Zhang FS, Hoffland E (2007) Mycorrhizal responsiveness of aerobic rice genotypes is negatively correlated with their zinc uptake when nonmycorrhizal. Plant Soil 290:283-291

Gianinazzi S, Gollotte A, Binet MN, van Tuinen D, Redecker D, Wipf D (2010) Agroecology: the key role of arbuscular mycorrhizas in ecosystem services. Mycorrhiza 20:519-530

Gosling P, Hodge A, Goodlass G, Bending GD (2006) Arbuscular mycorrhizal fungi and organic farming. Agric Ecosyst Environ 113:17-35

Hajiboland R, Aliasgharzadeh N, Laiegh SF, Poschenrieder C (2010) Colonization with arbuscular mycorrhizal fungi improves salinity tolerance of tomato (Solanum lycopersicum L.) plants. Plant Soil 331:313-327

Helgason T, Daniell TJ, Husband R, Fitter AH, Young JPW (1998) Ploughing up the wood-wide web? Nature 394:431-431

Hetrick BAD, Wilson GWT, Cox TS (1992) Mycorrhizal dependence of modern wheat-varieties, landraces, and ancestors. Can J Bot 70:2032-2040

Hetrick BAD, Wilson GWT, Todd TC (1996) Mycorrhizal response in wheat cultivars: relationship to phosphorus. Can J Bot 74:19-25

Hijri I, Sýkorová Z, Oehl F, Ineichen K, Mäder P, Wiemken A, Redecker D (2006) Communities of arbuscular mycorrhizal fungi in arable soils are not necessarily low in diversity. Mol Ecol 15:2277-2289 
Janos DP (2007) Plant responsiveness to mycorrhizas differs from dependence upon mycorrhizas. Mycorrhiza 17:75-91

Johnson D, Leake JR, Read DJ (2001) Novel in-growth core system enables functional studies of grassland mycorrhizal mycelial networks. New Phytol 152:555-562

Johnson D, Leake J, Ostle N, Ineson P, Read D (2002) In situ ${ }^{13} \mathrm{CO}_{2}$ pulse-labelling of upland grassland demonstrates a rapid pathway of carbon flux from arbuscular mycorrhizal mycelia to the soil. New Phytol 153:327-334

Kaeppler SM, Parke JL, Mueller SM, Senior L, Stuber C, Tracy WF (2000) Variation among maize inbred lines and detection of quantitative trait loci for growth at low phosphorus and responsiveness to arbuscular mycorrhizal fungi. Crop Sci 40: 358-364

Kitson RE, Mellon MG (1944) Colorimetric determination of phosphorus as molybdivanadophosphoric acid. Ind Eng Chem Res Anal Edi 16:379-383

Klironomos JN (2003) Variation in plant response to native and exotic arbuscular mycorrhizal fungi. Ecology 84:2292-2301

Leifheit EF, Verbruggen E, Rillig MC (2014) Rotation of hyphal in-growth cores has no confounding effects on soil abiotic properties. Soil Biol Biochem 79:78-80

Lekberg Y, Koide RT (2005) Is plant performance limited by abundance of arbuscular mycorrhizal fungi? A metaanalysis of studies published between 1988 and 2003. New Phytol 168:189-204

Liu SL, Guo XL, Feng G, Maimaitiaili B, Fan JL, He XH (2016) Indigenous arbuscular mycorrhizal fungi can alleviate salt stress and promote growth of cotton and maize in saline fields. Plant Soil 398:195-206

Oehl F, Sieverding E, Ineichen K, Mäder P, Boller T, Wiemken A (2003) Impact of land use intensity on the species diversity of arbuscular mycorrhizal fungi in agroecosystems of Central Europe. Appl Environ Microbiol 69:2816-2824

Oliveira CA, Sá NM, Gomes EA, Marriel IE, Scotti MR, Guimarães CT, Schaffert RE, Alves V (2009) Assessment of the mycorrhizal community in the rhizosphere of maize (Zea mays L.) genotypes contrasting for phosphorus efficiency in the acid savannas of Brazil using denaturing gradient gel electrophoresis (DGGE). Appl Soil Ecol 41:249-258

Plenchette C, Fortin JA, Furlan V (1983) Growth-responses of several plant-species to mycorrhizae in a soil of moderate Pfertility. 1. Mycorrhizal dependency under field conditions. Plant Soil 70:199-209

Poorter H, Fiorani F, Pieruschka R, Wojciechowski T, Putten WH, Kleyer M, Schurr U, Postma J (2016) Pampered inside, pestered outside? Differences and similarities between plants growing in controlled conditions and in the field. New Phytol 212:838-855

Ryan MH, Graham JH (2002) Is there a role for arbuscular mycorrhizal fungi in production agriculture? Plant Soil 244: 263-271
Sanders IR (2003) Preference, specificity and cheating in the arbuscular mycorrhizal symbiosis. Trends Plant Sci 8:143145

Sangabriel-Conde W, Maldonado-Mendoza IE, Mancera-Lopez ME, Cordero-Ramirez JD, Trejo-Aguilar D, NegreteYankelevich S (2015) Glomeromycota associated with Mexican native maize landraces in los Tuxtlas, Mexico. Appl Soil Ecol 87:63-71

Sasvari Z, Laszlo H, Posta K (2011) The community structure of arbuscular mycorrhizal fungi in roots of maize grown in a 50year monoculture. Biol Fertil Soils 47:167-176

Sieverding E, Toro S (1988) Influence of soil-water regimes on va mycorrhiza .5. Performance of different vam fungal species with cassava. J Agron Crop Sci 161:322-332

Smith SE, Read DJ (2008) Mycorrhizal Symbiosis, 3rd edn. Academic, New York, pp 1-769

Tawaraya K (2003) Arbuscular mycorrhizal dependency of different plant species and cultivars. J Soil Sci Plant Nutr 49:655668

Tawaraya K, Tokairin K, Wagatsuma T (2001) Dependence of Allium fistulosum cultivars on the arbuscular mycorrhizal fungus, Glomus fasciculatum. Appl Soil Ecol 17:119-124

Trouvelot A, Kough JL, Gianiazzi-Pearson V (1986) Mesure du taux de mycorrhization VA d'un système radiculaire. Recherche de methodsd'estimation ayant une signification fonctionnelle. In: Gianinazzi-Pearson V, Gianinazzi S (eds) Physiological Genetical aspects of mycorrhizae. INRA Press, Paris, pp 217-221

Van der Heijden MGA (2002) Arbuscular mycorrhizal fungi as a determinant of plant diversity: in search of underlying mechanisms and general principles. In: Van der Heijden MGA, Sanders I (eds) Mycorrhizal ecology. Ecological studies, vol 157. Springer-Verlag, Berlin, pp 243-265

Wang XJ, Wang XX, Feng G (2015) Optimised nitrogen fertiliser management achieved higher diversity of arbuscular mycorrhiza fungi and high-yielding maize (Zea mays L.). Crop Pasture Sci 66:706-714

Wilson GWT, Hartnett DC (1998) Interspecific variation in plant responses to mycorrhizal colonization in tallgrass prairie. Am J Bot 85:1732-1738

Wright DP, Scholes JD, Read DJ, Rolfe SA (2005) European and African maize cultivars differ in their physiological and molecular responses to mycorrhizal infection. New Phytol 167: 881-896

Zhang T, Shi N, Bai DS, Chen YL, Feng G (2012) Arbuscular mycorrhizal fungi promote the growth of Ceratocarpus arenarius (Chenopodiaceae) with no enhancement of phosphorus nutrition. PLoS One 7:e41151

Publisher's note Springer Nature remains neutral with regard to jurisdictional claims in published maps and institutional affiliations. 